\title{
Living off the Grid
}

\author{
Eric Outram* \\ Grant MacEwan University, Canada
}

\begin{abstract}
Living in the city most people take for granted the convenience of flicking on a light switch or plugging in an appliance. They also expect to be able to call the utility company if there is no heat for the house. Now imagine being responsible for providing all of your survival needs from electricity through waste management. This is off-grid living.

The settlers who came here to Canada lived off-grid. Homes were often built of sod, heated with wood-fired stoves, and lit with candles they made themselves. The majority of twenty-first century Canadians would perish in similar living conditions. The Canadian Encyclopaedia in its history of Western and Northwest Canada describes the lives of the pioneer homesteaders who purchased 160 acres of land for $\$ 10$ and struggled to survive. "Homesteaders and their families were often separated from friends and relatives, and many suffered years of hardship and loneliness. One of the greatest difficulties was the absence of roads and bridges. Most trails were impassable when wet. Medical care was scarce and farm injuries were often crippling or fatal, and many simple ailments caused prolonged hardship. For many settlers the price of homesteading was too high, they cancelled their claims and moved away" (McCracken, 2011). Today, off-grid living is sought out for different reasons.

People who decide to live off-grid are often looking for a way to live in harmony with and lessen their impact on the environment. They enjoy a physical challenge, and/or appreciate some solitude. It is possible to lessen reliance on the grid and still live in the city, but it is expensive and more difficult due mainly to regulatory requirements. Since regulations vary widely among municipal jurisdictions the focus of this article is development of an off-grid living facility where municipal services are unavailable.
\end{abstract}


Off-grid living in its simplest form involves finding ways to provide for basic human comforts. "Off-grid also means not using or depending on public utilities, especially the supply of electricity," (Oxford Dictionary, 2011). For many people who are living this lifestyle it also involves growing food, raising chickens for eggs and meat, goats or cows for milk, and pigs for pork, bacon and ham. Off-grid living also means changing lifestyle to suit the season. Spring is planting season and that is the focus of activity. Summer means long days and a chance to build and do maintenance and time to cut, split and stack next year's firewood if the primary source of heat is wood-burning stoves. Fall is harvest time with its many hours of work preserving the food. Winter is for cocooning and making plans for the next growing season. If power generation is solar based, it probably means going to bed early and sleeping later to conserve energy.

A Personal Choice to Live Sustainably

The author and some of his family are in the process of developing a multigenerational home site on ten acres of forested property on the North Sunshine Coast of British Columbia, Canada. This article presents information that a family needs to consider when deciding to live off-grid. It then presents a case study of the decisions, considerations, and expectations that the author's family encountered when building the home site; including real-world suggestions and solutions based on primary research done by the family members. It also gives some site-specific details of that ongoing work.

\section{Design Considerations}

When deliberating about off-grid living, the main areas of functional consideration are power, heat, water supply, and waste disposal. Power can come from three main sources: solar, wind, or water. Wind and water sources are used to turn some form of turbine or generator that can be hooked up to battery storage. Solar panels, or photovoltaic units are mounted on the house and convert the sun's energy into power that is then stored in batteries for ongoing use. Site parameters will determine the best power source for a particular project (Oke \& Oke, 2008b, p. 78). If the site has a reliable flowing source of water, then installing a micro-hydro system is a very efficient way to generate power. Solar panels need a good open southern exposure to best take advantage of the sun, and wind power requires a very open space in the direction of the prevailing winds. 


\section{Power}

"The average Canadian household consumes in excess of 8,500 kilowatt hours (KWh) of electricity in a year where the heat source is something other than electricity" (Canada N. R., 2009). To put that in perspective, one 60 watt light bulb burning for one thousand hours uses 60 kilowatt hours of electricity. A modern micro-hydro system using one turbine can produce up to $8,400 \mathrm{KWh}$. The definition of a micro-hydro

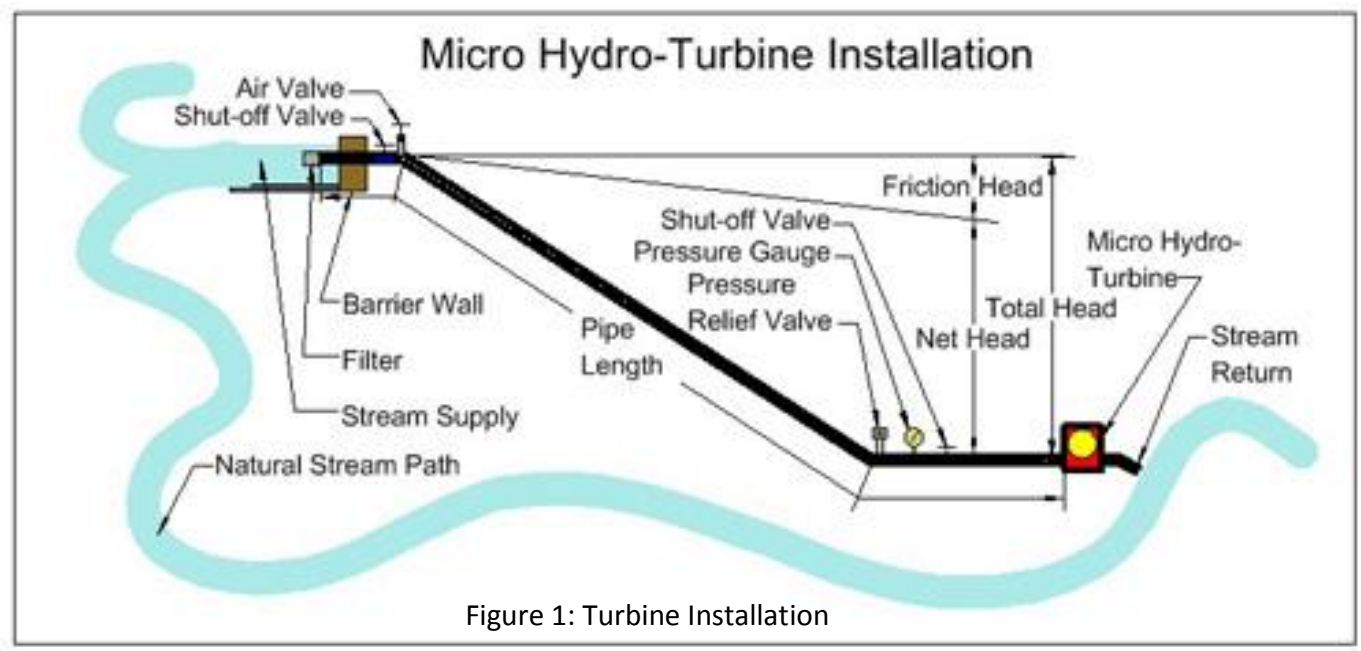

system is the use of flowing water to turn a water turbine that generates electricity in an alternator (Figure 1). It can also be described as a "run of river" system. Sizing a microhydro system is fairly simple and there are many online resources to assist in this. Lifestyle is the major factor in determining electrical requirements. Every light and additional appliance adds to the load on the system. Micro-hydro systems are relatively simple to install. They require an intake, usually built into a dam or weir, a penstock, which is the pipe between the intake and the turbine, and the turbine itself.

Micro Hydro Systems follow the same basic design parameters. The elevation difference between the intake and the turbine, or head, is a major factor in determining how much power will be generated. The other critical factor is flow. Any combination of high head and low flow, or low head and high flow will work to produce power. This means that micro-hydro systems can be used under a wide range of conditions. Microhydro system components are readily available from Canadian sources. One supplier is Energy Alternatives Ltd. a Vancouver, British Columbia company that sells packages to suit most off-grid users. Packages include the turbine, charge controller, instrumentation and inverter. Systems can be designed to operate at 12, 24, or 48 volts.

Before the advent of the modern Micro-hydro system and its adoption by many offgrid users, people built a version based on the Pelton Wheel, a very efficient variation of 
the more traditional water wheel. "In Pelton's impulse wheel, water pressure is turned into kinetic energy by pushing the water through a nozzle. The resulting water jet impacts the curved turbine blades, reversing the water's flow and causing the runner to spin. This proved to be a more effective design for converting the energy in water flow to useful work than previous convertors. The impulse turbine was especially welladapted for high head sites" (Cleveland, 2008).

Wind power generation is less reliable in many locations than either solar or microhydro. In heavily treed areas, it is very difficult to take advantage of wind flow unless the unit is constructed above the trees or a very large clearing is available. The biggest disadvantage in most locations is that the wind just does not blow constantly enough, or with sufficient velocity (Oke \& Oke, 2008).

Utilities for an average home vary, but even a conservative user will pay hundreds of dollars a month and the cost will continue to escalate. Living off-grid means an initial outlay for equipment, but monthly payments become a thing of the past. Improved technology has given battery and photovoltaic panels a fifteen to twenty-year useful life expectancy.

\section{Construction}

Constructing an off-grid home means looking very carefully at the location and orientation of the house to take advantage of the site's natural attributes. One technique or method that can be helpful is to use passive solar gain as a design parameter. "Solar energy is a radiant heat source that causes natural processes upon which all life depends. Some of the natural processes can be managed through building design in a manner that helps heat and cool the building. The basic natural processes that are used in passive solar energy are the thermal energy flows associated with radiation, conduction, and natural convection. When sunlight strikes a building, the building materials can reflect, transmit, or absorb the solar radiation. Additionally, the heat produced by the sun causes air movement that can be predictable in designed spaces. These basic responses to solar heat lead to design elements, material choices and placements that can provide heating and cooling effects in a home. Passive solar energy means that mechanical means are not employed to utilize solar energy" (Passive Solar Design, 2011).

Passive solar gain is a combination of taking advantage of the heating effects of the sun, using thermal mass to store heat to be dissipated later, and using the relative location of windows, walls, and trees to assist in cooling during hot weather (Oke \& 
Oke, 2008). South and west exposures are great for taking advantage of sun warming. Using the best windows for the job means triple pane, low emissivity glass that will slow the heat loss or gain.

Active solar heating requires the use of fans and pumps to distribute the heat acquired through passive solar gain. This type of system can be effective provided the gain outstrips the need for power to operate it. Active solar heating is usually accomplished using a sealed piped water system that is exposed to the sun from behind glass. A combination of gravity and pumps then circulates the warmed water through heat exchangers to release the energy in the form of heat. The process is complete when the cooled water returns to be reheated (Oke \& Oke, 2008).

Construction standards vary from location to location due mainly to climatic differences. Building an off-grid house to the minimum prevailing standards is an approach that will be counter-productive in the long run. Paying a small premium at the construction phase returns large dividends over the life of the building. Taking care to make the building envelope as tight and well insulated as possible reduces the energy required to heat or cool interior spaces throughout the changing seasons.

From first-hand experience and research, it is strongly recommended that proper insulating materials and techniques be used. " $R$ values and their metric equivalent, RSI values, are a way of labelling the effectiveness of insulating materials. The higher the $R$ value or RSI value, the more resistance the material has to the movement of heat. Insulation products sold in Canada are labelled with R and RSI values. Provincial building codes specify minimum R (or RSI) values for new construction. Different values are used for different applications" (Canada Mortgage and Housing Corporation, 2011). The higher the number, the better the material slows heat loss. Using R45 insulation in the roof and R25 in the walls, as well as inserts in all the electrical outlets and switchboxes ensures maximum heat retention. Using a heavy-duty vapour barrier sealed to the framing helps prevent heat loss. All joins and gaps are sealed with tape, and the plastic is sealed to the framing. The compound for sealing the vapour barrier is extremely sticky and designed to remain flexible for a very long time. The problem with handling it is that if you get any on you it is almost impossible to get it off. Don't get the black gunk on you!

This level of insulation and the air tightness of the house envelope give the opportunity to heat with efficient, smaller wood-burning stoves and to use less fuel than many size-comparable houses. This is important when considering the amount of work to put up a year's supply of fuel.

ECJ Volume 1, No. 1, 2011 


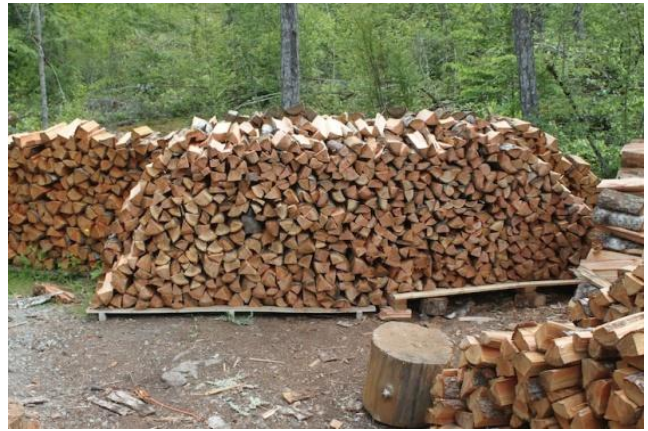

Figure 2 - Split firewood stacked to dry.

The amount of fuel required for a wood stove in a year will vary greatly depending on local climatic conditions. On the British Columbia coast, winters are mild and dwellings only require added heat for about six months out of the year, and for many of those months it is only partial days. Living in the interior or more northern parts of the province might require supplies for up to eight months for full time heating (Figure 2). Stoves are generally more efficient than fireplaces. Modern stoves with catalytic converters can be banked up at night with a full firebox of fuel and will burn all night.

\section{Water}

A reliable water supply is essential to living anywhere, and living off-grid means ensuring that a safe and reliable source of potable water is available. It is possible to use a lake, stream, or river for supply if one is available, but in many cases a drilled well is the most likely source. The downside of a drilled well, other than the cost, is the need for power to pump the water to the house for use. Depending on location, it is possible to supplement water supply by collecting and storing rain or melt water.

Sewage treatment and disposal options have to be carefully considered due to the possibility of contamination to water sources. Smaller dwelling units can be equipped with compostable toilets. These are environmental units that treat the waste and make it possible to use it for adding to growing areas. Larger houses with more than a couple of occupants will require a septic system because the loading is too great for a composting unit. The septic system would either be the evaporation mound type or a piped field. The nature of the land it is installed on will determine the final design. Septic drainage fields require about five feet of material above bedrock in order to filter properly while evaporation mounds are constructed above grade using fill (Ministry of Health, 2006).

\section{Challenges and Dangers}

Living off-grid in a forested environment presents some challenges that urban dwellers will likely never face. Fire! The threat of a forest fire destroying a home in this 
setting is very real. The choice of construction materials is influenced by this reality. The roof of choice is metal, and under no circumstances should a vinyl siding be used as it melts when heated and releases dioxins that are poisonous if inhaled. Non-flammable fibre cement siding is a great choice as it is a greener product both in production and disposal. Insurance against fire is either impossible to get or prohibitively expensive so off-grid dwellers generally have to take what precautions they can when there is no hydrant within ten kilometres. Clearing the underbrush from the immediate vicinity of the house is the simplest solution to keeping fire at bay. Forest fires often flash through the tops of trees and the metal roof means fire has no way to get a hold as it might if it is constructed with shingles or shakes.

\section{A Case Study: Living Research (primary field research)}

\section{Our Dream}

The following is a case study of the author and his family's collective and conscious decision to live offgrid. Given that the family members live within the research environment, primary research approaches in the form of family discussions and decision-making, experimental research through trial and error practices during development of the home site and construction of the buildings, and critical information from various sources including local businesses and dwellers are explained and described in this section. Comprehensive explanations of the author's first-hand account of living off-grid, as well as his reflections on the choices that were made to live off-grid are described below.

In our family, it has long been contended that earth's population is consuming resources faster than they can be replenished. I have been forbidden to instigate discussions on this topic at parties because of the negative reaction of many people to the suggestion that we will eventually be in dire straits caused by our excessive consumption.

Currently a resident of St. Albert, Alberta, I was appalled to read some of the statistics in the City of St. Albert's recently published report on the environment and its progress towards meeting environmental standards previously put into place. For me the most disturbing statistic was related to St. Albert's ecological footprint. "The earth is finite. There are only 1.8 hectares of land and sea resources available to support each person on the planet. The 
average person on the planet has an ecological footprint of 2.8 hectares. The Canadian average is 7.8 bectares per person, while St. Alberta's is 11.7 hectares" (St. Albert Gazette, 2011). This means that each citizen in St. Albert is using more than six times his or her share of the planet's available resources.

\section{Researching Property Site for Off-Grid Living}

When our family started looking for a property to develop as a three generational, self-sustaining retreat for our large extended, blended family, we had not considered offgrid living. The decision to buy a property with no connection to the grid was decided for us after an extensive search for serviced land meeting our basic requirements came up with nothing affordable.

Our criteria was for about ten acres of land with minimal or no restrictions on the type or amount of buildings, oceanfront or ocean view, and a chance to grow and raise much of our own food. We never seriously considered the East coast of Canada due to its remote relationship to our long-time home and friends and family in Alberta. British Columbia beckoned.

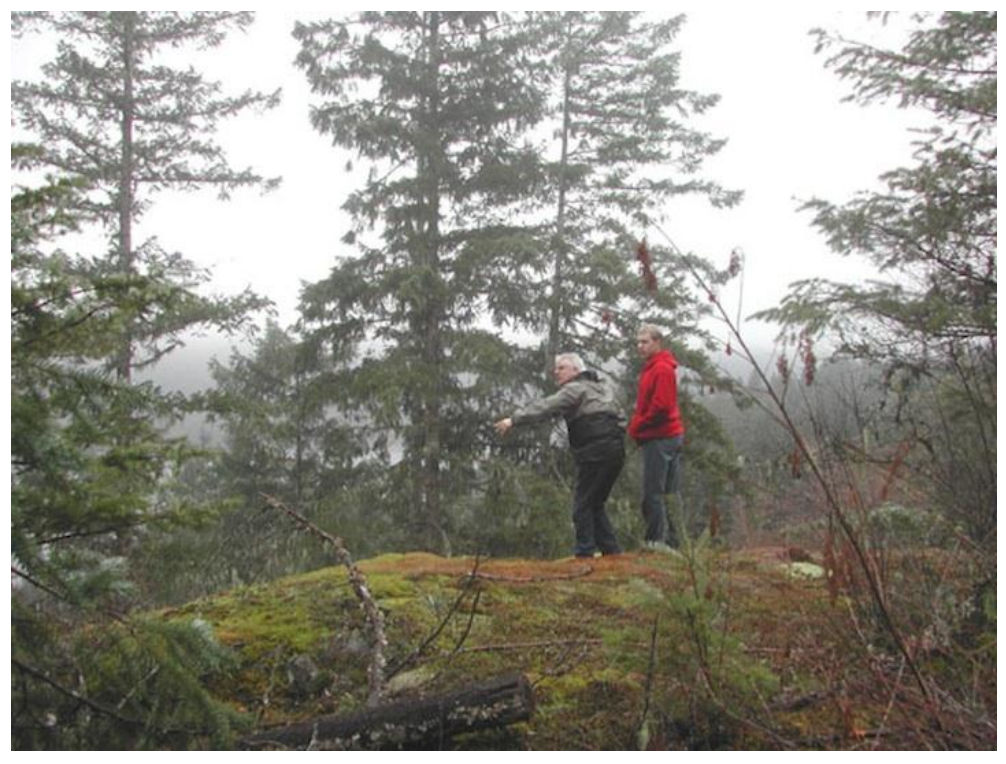

Figure 3 - Inspecting the land before the purchase

We found the land by chance on the Internet the day it went on the market. It was not serviced, but as yet we had no idea what that would mean in terms of building and living on the property. We made an offer subject to inspecting the property. The property is ten kilometres from the highway along a gravel forestry service road. The nearest power line is eight kilometres away and there are no municipal services available. The inspection consisted of walking, a relative term as the property is steep and the underbrush thick; perhaps clambering would be a better description, across the property 
from different directions and trying to picture the overall shape (Figure 3). I have a background in municipal engineering from a twenty-five year stint with various companies and my son-in-law is a qualified building construction supervisor and inspector, so we felt confident in assessing the potential of the land. If you do not have that kind of expertise, then I would recommend hiring someone qualified to provide you with a report on the possibilities for the land, and to get an honest assessment of the associated problems. Our probing identified a number of bedrock outcroppings that would make great home sites and discovered areas that could be opened up for cultivation.

The climatic conditions for the North Sunshine Coast show a microclimate capable of sustaining a Growing Zone 8 designation. By comparison, Edmonton, Alberta is a Growing Zone 3 to 4. "The Plant Hardiness Zones map outlines the different zones in Canada where various types of trees, shrubs and flowers will most likely survive. It is based on the average climatic conditions of each area. The first such map for North America, released by the United States Department of Agriculture in 1960, was based only on minimum winter temperatures. In 1967, Agriculture Canada scientists created a plant hardiness map using Canadian plant survival data and a wider range of climatic variables, including minimum winter temperatures, length of the frost-free period, summer rainfall, maximum temperatures, snow cover, January rainfall and maximum wind speed" (Canada N. R., 2003).

"Natural Resources Canada's Canadian Forest Service scientists have now updated the plant hardiness zones using the same variables and more recent climate data (196190). They have used modern climate mapping techniques and incorporated the effect of elevation. The new map indicates that there have been changes in the hardiness zones that are generally consistent with what is known about climate change. These changes are most pronounced in western Canada" (Canada N. R., 2003).

The property that we inspected is capable of growing many varieties of fruits and nuts that will not grow on the northern prairies. A quick survey of the area revealed that walnuts, kiwis, peaches and, of course, the more mundane apples, pears, and plums grow in the immediate vicinity. Blackberries are so common and plentiful that many people treat them as a nuisance.

Based on our thorough inspection, we decided to purchase the land. 


\section{Building Off-Grid Structures}

My son-in-law and I started the construction with a dwelling unit we affectionately call "the cabin." It is a one-thousand square-foot, two-bedroom home with a loft, heated by a wood burning stove. Our daughter, son-in-law, and four grandchildren ranging in age from two to ten years of age currently live there.

As we spend more time around the property a development plan is evolving. From the beginning, the plan has been to develop a house on the site that would be home to three generations living together, but in separate wings, with a communal kitchen, and a shared great hall. The first cabin will become guest accommodation once the main house is habitable. The big house is now framed, roofed, and it has the windows and doors in place. This fall will see the installation of the plumbing, electrical, and the heating. By spring, the insulating and drywall will be complete and we will be close to moving in. Not bad for a dream that started only five years ago!

We found a site close to the main entrance of the property to build our workshop and garage. We only needed to clear brush before starting to build, and it is screened from the road by a stand of trees affording plenty of privacy and security. The workshop is topped off with a two-bedroom apartment that another family member will live in.

\section{Researching a Plan}

In opening up the land to build the first dwelling, we optimized a sixty-year-old skidder trail. Skidders are heavy hauling equipment used in rough terrain to pull felled trees out to a collection site. The trail had been used to remove old-growth timber from the property. It was overgrown but distinct enough to follow and linked three of our potential building sites. No trees were sacrificed. For the first couple of years, it was only suitable for the quad or foot traffic. The first dwelling unit, a thousand square foot, twobedroom cabin with a loft was constructed furthest from the entrance to the property with all the materials transported on the quad or carried (Figure 4). 


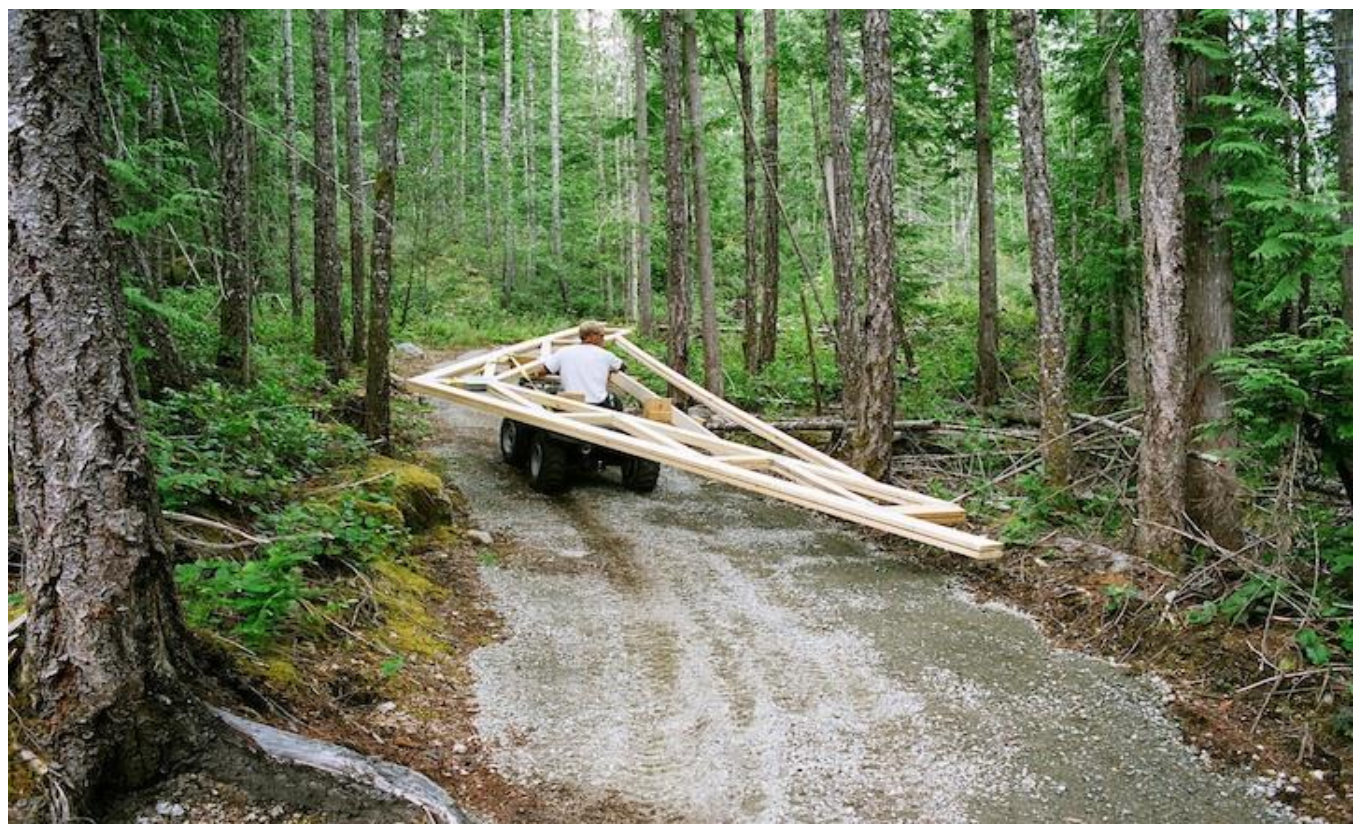

Figure 4 - Using the Quad to transport building materials

People often assume that since the property is treed, isolated, and off-grid that the dwelling units are going to be log construction. We chose traditional wood framing methods for this project because we have no experience in log home building. Also, there is a definite downside when it comes to insulating, installing plumbing and electrical, and interior finishing in a log house. We do have a mill and use it to cut lumber for posts and beams, interior and exterior trim, and hardwood floors (Figure 5).

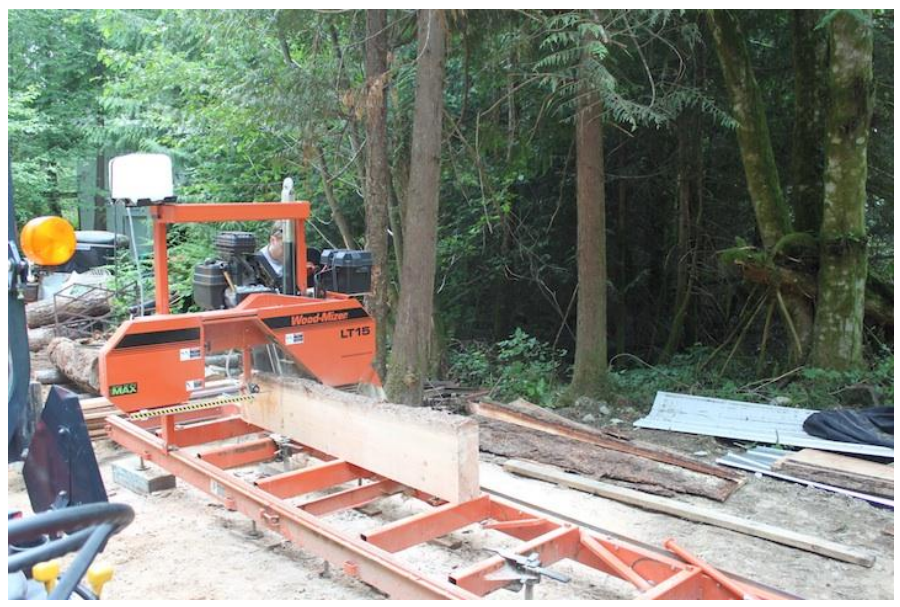

Figure 5 - Milling a Cedar beam from a tree felled by the Forestry
We considered trying to incorporate recycled materials into our construction in order to lower our environmental footprint, but practical considerations took precedence. There was no readily available source for most of the material we needed in the quantities we required. The best we could hope to achieve through careful planning was to avoid waste. 


\section{Deciding the Power Source}

Power supply is not a major problem for this development. Fortunately, there is a creek that runs through our property that is considered seasonal, and therefore not subject to the same degree of regulation as a permanent or a fish-spawning watercourse. We can rely on sufficient flow in the creek to drive our turbines for nine months of the year. The other three months are in late summer and the increased hours of sunshine provide adequate power for our solar panels. Summer also means that our power load is greatly reduced. The elevation change across

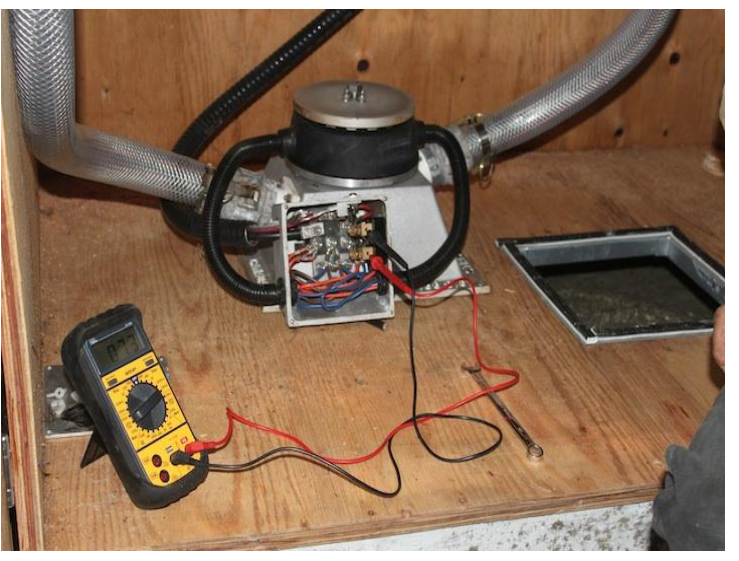

Figure 6 - Turbine installed in turbine house. Water enters through the two clear pipes and drains out under the turbine. our site is approximately 65 meters (200 feet), which is sufficient head to generate all the power we require.

Our particular system is designed so that we can power all of our buildings with our own electrical grid, albeit a small one. This means we have to take into account distribution losses as well as loading. The turbine house at the lower end of the system needed to be situated on a flat surface above the turbulent flow of the creek with easy access to the turbine and its electrical connections for servicing purposes. Since the banks of the creek are steep at the lower end, sites were few (Figures 6 and 7).

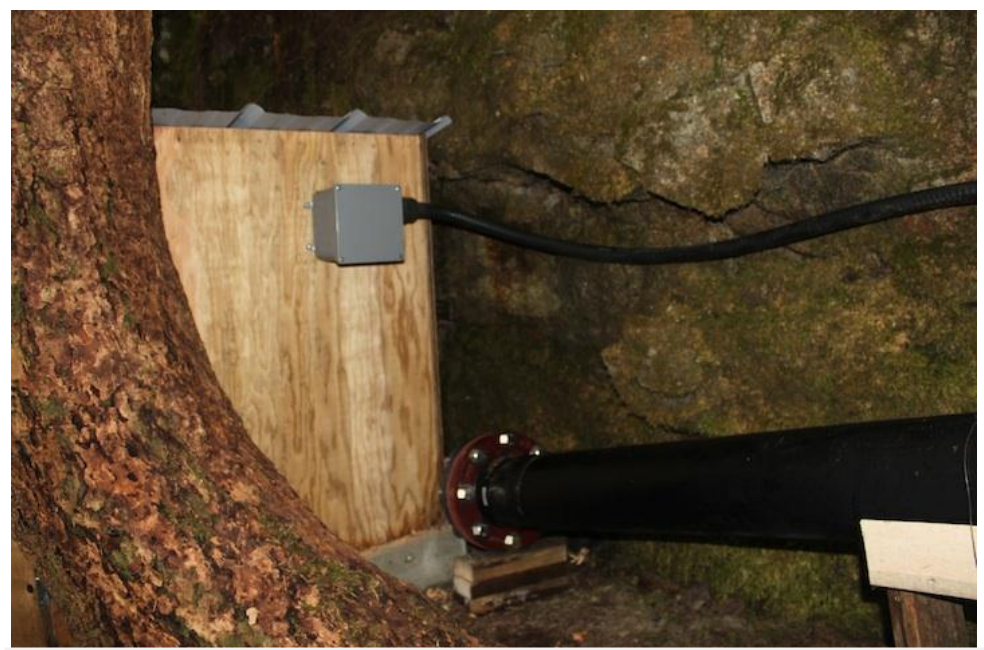

Figure 7 - Turbine house built on rock ledge and protected from washout by a tree.
The intake site was determined by two factors: 1) calculating the height of head required to maximize output from the turbine, and 2) working up the creek until we found a suitable spot to build the intake dam. 
The fun part was wrestling four hundred feet of semi-rigid pipe up the steep, rocky, and obstructed creek bed. It was impossible to get enough access to join the pipe in place; so, we pre-joined it into two, two-hundred foot lengths and hauled it into place using rope, pulleys, and in one instance the quad. Physics and applied mechanics are wonderful tools.

We installed a six-inch diameter pipe that would ensure enough flow to power two turbines, giving us the potential to produce $16,800 \mathrm{KWh}$. Our current system produces 24 -volt direct current to battery storage, which is then inverted to a household 120 -volt alternating current. This allows for the use of regular appliances as opposed to more expensive specialized equipment.

The micro-hydro setup installed on our property requires that all the power is used as it is produced, or stored. The system runs twenty-four hours a day unless the flow of water to the turbine is physically stopped. Once the batteries are fully charged, the system can be designed to automatically direct the excess power to a hot water heater. When both of the batteries are charged, and the water heated, then the power needs to be directed to a space heater or some other device for dissipation. Nothing is wasted.

\section{Heating and Cooling}

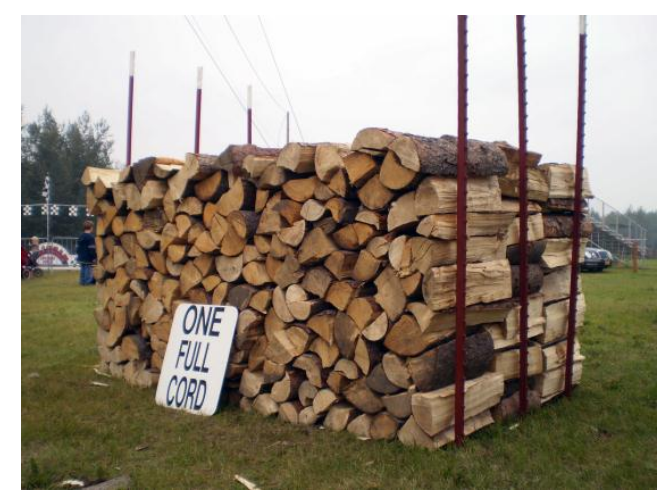

The houses all have great south and west exposures to take advantage of passive solar gain. Finishing of floors, fireplace hearths, and chimneys is designed to add thermal mass which will store heat during the day and release it back into the rooms as the outside air cools. This natural phenomenon means that fires will need to be used less and we will use significantly less firewood.

Figure 8 - A cord of firewood

Wood burning stoves in the smaller dwelling units, and a wood burning boiler in the big house provide all the heating. This means cutting and stacking approximately three cords of wood each year for fuel. A cord of wood is a stack of split logs measuring eight feet long by four feet wide by four feet high (Figure 8). 
Our practice is to clear out deadfall on the property first and supplement that with trees from Crown land. The forestry service issues free "own use" permits for taking wood from Crown land. For best results wood needs to be split and left for a year before

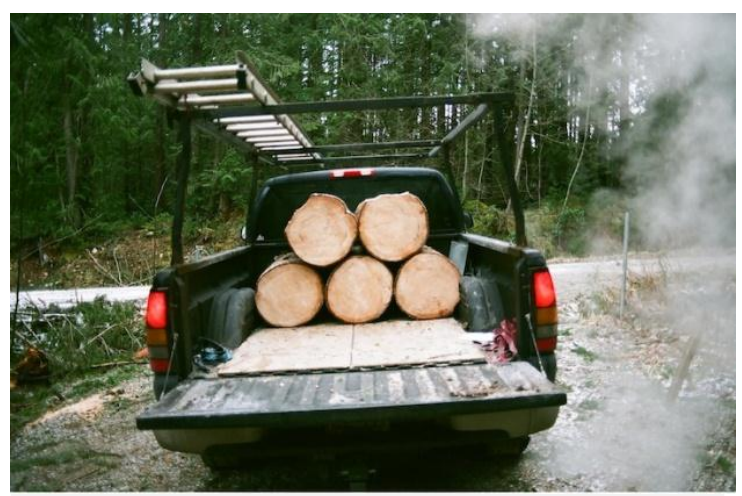

Figure 9 - A wind felled tree cut in sections for transport

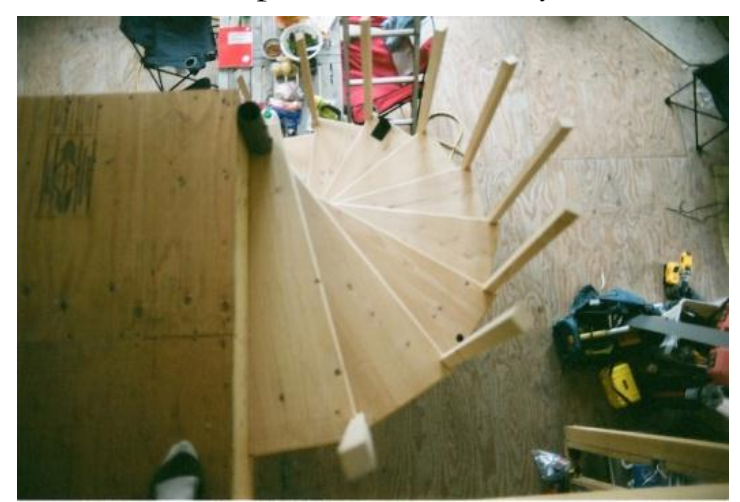

Figure 10 - Spiral staircase made from downed tree and installed in the cabin.

burning, so we need to have a two-year supply stockpiled at all times. A high windstorm downed a one hundred foot tree across the entrance to the property and we had to clear it before we could drive out (Figure 9). Cutting it into ten-foot lengths allowed us to manhandle it to the side. Before leaving, we cut five sections forty inches long and transported them back to St. Albert where, in our garage, they were made into a spiral staircase for the cabin (Figure 10). Nothing is wasted. Tall trees within one hundred and fifty feet of the house pose a problem if fire occurs or during high winds, but we have decided that taking them all down would defeat the purpose of living in the forest. Clearing out the underbrush to prevent ground fires seems like a reasonable compromise.

\section{Water Sustainability}

The creek is our primary source of water, but due to intermittent flow in the summer and our lack of historical data, we have some reservations.

The metal roof, because it remains relatively clean, will be used to collect rainwater into a fifteen hundred gallon cistern buried under the garage slab. This water is designated for firefighting or irrigation, but in an emergency and with additional filtration it could also be used for domestic purposes. There is a similar tank that will hold treated creek water for domestic use. 
The possibility of drilling a well is still under consideration, although this means drilling into bedrock. "Witching" for water is a process that looks and feels like a dark art form. Witching or divining for water is accomplished by walking around the property with some form of divining rod, old-timers prefer a forked Hazel branch that will pull towards the ground if water exists in quantity below the surface. I prefer to use two metal rods bent at right angles and held loosely in my fists that indicate the presence of water by rotating to cross each other. Drilling into rock is expensive. Local companies are capable of reaching depths of seven hundred feet, but well drilling does not come with a guarantee of finding water and it is possible to invest as much as twenty thousand dollars into a well and come up dry. Some serious thought has gone into trying to sustain us using alternative sources of water to meet our potable water needs.

\section{Waste Disposal}

Waste disposal will be accomplished using a variety of methods. The smaller dwelling units are equipped with compostable toilets. These are environmental units that treat the waste and make it possible to use it for adding to growing areas. The main house will have a septic system because the loading is too great for a composting unit. The type of septic system is still to be determined. We have located two possible sites and now have to test the ground to decide whether we can use a field, our first choice, or if we need to go to an evaporation mound.

The plumbing in all the buildings is separated so that the grey water can be reused for irrigation. Grey water gardens are a feature on the downhill side of each building. There are a great variety of plants that thrive with constant watering. The greatest advantage gained from separating grey water is the reduction in size of the septic system. In our case with the sloping rocky terrain, we might not have found a suitable site for a field or mound to treat all our wastewater.

\section{Resources}

Plans for the west-facing courtyard include, amongst other things, a wood-fired clay oven, raised planters, multi-level decks, and an outdoor kitchen. These ovens have been used for hundreds, if not thousands, of years by people worldwide. They are cheap to construct from locally found materials, and designs can be as varied as the individuals who build them. A clay oven, if properly utilized, is an amazing energy saver. One firing 
using a handful, well maybe an armful, of wood and proper preparation make it possible to cook a large variety of foods, and the last thing you do is to dry the wood for the next firing.

We are recycling the metal framework of a commercial greenhouse from a site in Edmonton. Keeping in mind that we will have to heat the greenhouse during the winter, the working surfaces will be poured concrete slabs to provide thermal mass that will absorb heat when the sun is shining, store it, and release it back into the air as the ambient temperature drops. Design and layout are being carefully planned to make best use of passive solar gain.

Planning for garden spaces involves not only deciding what to grow and where to grow it, but also ensuring that crops, animals, and small children are protected from deer, bears, raccoons, eagles, cougars, and a myriad of other creatures and bugs. The science of growing certain crops together for their mutual protection is the subject for a different article. Fences, both natural and human-made - that's where the pesky blackberries will come in handy, are necessary if we are to enjoy the fruits of our labour.

Although we are not able to significantly reduce our environmental footprint during the construction phase of this development, we are confident that what we have done is to ensure that the nine of us who will initially live on the property will significantly contribute in the future. Our lifestyle choice has made us acutely aware of our power and water usage, and our connection to the environment. Our commitment to growing more of our own food will bond us more closely to the land. The best outcome from these choices, beside the incredible enjoyment we derive from working and living in the forest, is the environmental awareness that our grandchildren are exhibiting. The future of our little corner of the world will be in good hands.

* Author: Eric Outram is a graduate from the Bachelor of Applied Communications in Professional Writing degree program at Grant MacEwan University, Canada. He has published in various publications, including Conservation (Alberta, Canada). He now writes with the beanty of his familial land and the Pacific Ocean as his inspirations.

ECJ Volume 1, No. 1, 2011 


\section{References}

Canada Mortgage and Housing Corporation. (2011). Insulating Your House. Retrieved August 18, 2011, from Canada Mortgage and Housing Corporation: http://www.cmhc-schl.gc.ca/en/co/maho/enefcosa/enefcosa_002.cfm

Canada, N. R. (2000). Personal: Residential. Retrieved August 2011, from Office of Energy Efficiency: http://oee.nrcan.gc.ca/publications/infosource/pub/energy_use/sheu_e/index. $\mathrm{cfm}$

Canada, N. R. (2003). Plant Hardiness Zones. Retrieved July 23, 2011, from The Atlas of Canada: http://atlas.nrcan.gc.ca/site/english/maps/environment/land/planthardi

Cleveland, C. S. (2008). Pelton, Lester Allan. Retrieved July 24, 2011, from Encyclopedia of Earth: http://www.eoearth.org/article/Pelton,_Lester_Allan

McCracken, J. (2011). History of Western and Northwest Canada. Retrieved August 10, 2011, from Canadian Encyclopedia:

http://www.thecanadianencyclopedia.com/index.cfm?PgNm=TCE\&Params=A 1ARTA0003824

Ministry of Health. (2000). Sewerage System Standard Practice Manual. Retrieved August 10, 2011, from Health Protection - Province of British Columbia: http://www.health.gov.bc.ca/protect/SPM20(Sept2006)consolidated.pdf

Oke, L. \& Oke (2008). Build Your Own Home. Home and Garden. Retrieved July 20, 2011, from Lulu: http://www.lulu.com/product/ file-download/build-your-ownhome/2656464?productTrackingContext=search_results/search_shelf/centre/5

Oke, L. \& Oke (2008). Living off the Grid in 2008. Retrieved July 20, 2011, from Lulu: http://www.lulu.com/product/file-download/build-your-ownhome/2395428?productTrackingContext=search_results/search_shelf/centre/3 \#detailsSection

Passive Solar Design. (2011). Retrieved August 10, 2011, from Sustainable Sources: http://passivesolar.sustainablesources.com/

St. Albert Gazette. (2011). City of St. Albert - 2010 Report on the Environment. St. Albert Gazette . St. Albert, Alberta, Canada: St. Albert Gazette. 